\title{
General Disturbances and their Correlation to the Eruption of Primary Dentition in Children between 5 and 30 Months Age Group of Belgaum City: An Epidemiological Study
}

\author{
${ }^{1}$ Santosh M Sholapurmath, ${ }^{2}$ Shigli L Anand, ${ }^{3}$ Shobha Deshpande \\ ${ }^{1}$ Reader, Department of Pedodontics and Preventive Dentistry, NG Halgekar Institute of Dental Sciences and \\ Research Center, Belgaum, Karnataka, India \\ 2Professor and Head, Department of Pedodontics and Preventive Dentistry, Modern Dental College, Indore, Madhya Pradesh, India \\ ${ }^{3}$ Former Professor and Head, Department of Pedodontics, KLE Institute of Dental Sciences, Belgaum, Karnataka, India
}

Correspondence: Santosh M Sholapurmath, Reader, NG Halgekar Institute of Dental Sciences and Research Center Belgaum, Karnataka, India, e-mail: pedosms@ rediffmail.com

\section{ABSTRACT}

Background and objective: The effect of teething on infants health has been debated for at least 5000 years and traditional beliefs on issue have still not been entirely supplemented by scientific finding. This study has tried to gather scientific information of systemic/clinical signs and symptoms in scientific manner. The objectives of this study were: (1) To describe the most frequent objective clinical manifestation during the eruption of primary teeth, e.g. fever, diarrhea, drooling, fever-drooling, fever-diarrhea, drooling-diarrhea. (2) To assess the correlation between systemic symptoms and eruption of various group of teeth, e.g. incisor, canine, molar.

Methods: The survey was conducted in 500 children between 5 and 30 months and registered at child development center, KLES's Hospital and Medical Research Center, Nehru Nagar, Belgaum, Karnataka. A specially structured questionnaire was applied with face-to-face interview. Information was relayed in yes or no manner of objective manifestation during eruption of primary incisor, canine and molar which included drooling, diarrhea, fever and combination of these symptoms. Data were analyzed by descriptive statistic and Chi-square analyses. Results: The study showed more number of children in group A (less than 12 months) manifested drooling symptoms. As the ages advances with group B (between 12 and 18 months), group C (between 18 and 24 months) and group D (above 24 months), clinical manifestation of saliva found to be reduced. The results of study showed that $87.78 \% ; 57.8 \% ; 57.55 \% ; 25.7 \%$; of children with erupting teeth demonstrated general clinical symptoms like drooling, diarrhea and fever. The presence of fever-diarrhea in this study within group A, group $B$, group $C$ and group $D$ showed highest number of children by the manifestation than any other codes evaluated in the study.

Interpretation and conclusion: P resent data demonstrate association between fever-diarrhea observed in all group consistently when marked numerically. As the age advances the fever-diarrhea from group C (between 18 and 24 months) and group D (above 24 months) rank second and third. This ranking in group A (less than 12 months) and group B (between 12 and 18 months) at its highest position and attributable to lower immunity of infants. Further, virology study should be conducted on subjects to demonstrate any possible occurrence of systemic disturbances.

Keywords: Eruption, Deciduous, Fever, Diarrhea.

\section{INTRODUCTION}

Teething was described in sixth and eighth century before Christ $(\mathrm{BC})$, and through many generation teething has been held responsible for variety of childhood illness. ${ }^{1}$

As the pediatric physician assumes responsibility for children's physical, mental and emotional responsibility from conception to maturity, the pediatric dentist should also be concerned about their oral and dental health with greater responsibility and attention to the biologic process and happenings around the orofacial-dental complexes. The effect of teething on infant's health has been debated for at least 5000 years and traditional beliefs on issue have still not been entirely supplemented by scientific finding. Sumerians believed teething and worm infestation were associated. They believed that teething led to childhood mortality, seizers, diarrhea, fever or other serious condition. ${ }^{2}$

Opinions about the local and systemic disturbances in teething in infants vary. Teething is almost certainly a little uncomfortable to child. The gingiva swells and tender on palpation just before the eruption. Fever, diarrhea, drooling, dermatitis, anorexia, constipation, restlessness and respiratory infection are the general symptoms that often appear associated with tooth eruption. ${ }^{3,4}$ Pain and inflammation of the eruption site as well as irritable behavior were al so described during tooth eruption. Most expressed opinions without any factual basis, there is no definite evidence to support the claim of accompanying temporary systemic disturbances. Teething complaints are confined almost exclusively to eruption of deciduous dentition. ${ }^{5}$ Tooth eruption is the process by which a tooth moves from site of development within the jaws to its final functional position in the oral cavity. Although the tooth itself seems to play no active role in the process, the dental follicle, which is a rich source of eicosanoids, cytokines and growth factors seems to be crucial. It is thus quite plausible that teething may lead to local symptoms which are inflammatory or irritative in nature. $^{6}$ 
This study has tried to gather information of systemic clinical signs and symptoms in scientific manner. Much of data on teething obtained from parents memories and opinion, which were subjective in nature. This subjectivity accounts and makes it to have baseline data through prospective study. Furthermore, very negligible data exist in the literature regarding differences in a systemic symptoms and eruption of different types of teeth.

Therefore, the purpose of study was to describe the most frequent objective clinical manifestation during eruption of primary teeth, e.g. fever-diarrhea-drooling, fever-drooling, fever-diarrhea, drooling-diarrhea and to assess the correlation between systemic symptoms and eruption of various groups of teeth, e.g. incisor, canine, molar.

\section{METHODOLOGY}

A $n$ epidemiological survey was conducted on systemic clinical manifestation during the eruption of primary teeth in children between the age 5 and 30 months was carried out in B el gaum, $\mathrm{K}$ arnataka, India. This study was conducted on 500 children between 5 and 30 months registered at Child Development Center, K LES's H ospital and M edical Research Center, N ehru nagar, B el gaum, K arnataka. A Il the children sel ected were from different socioeconomic groups belonging to different ethnic group and parents speaking different languages, $\mathrm{K}$ annada, $M$ arathi, Hindi, English. These children were from different parts of Belgaum city - N orth west, N orth east, South west, South east, and attending and procuring facilities extended by Child Development Center at KLES's Hospital and M edical Research Center, B elgaum.

A specially structured questionnaire was applied by faceto-face interview to all 500 subject's parents whose children were between age of 5 and 30 months. Data were obtained mostly from the mothers who were the accompanying parent most of time. Parents were asked to complete a short and simple questionnaire. Information was relayed in a yes/no manner about three objective manifestations noted during eruption of primary incisors, canines and molars, including fever, diarrhea, drooling and the combination of these symptoms.

\section{Questionnaire}

On format, there were six questions to each of which alternate No (0) and $Y$ es (1) was recorded. If for the first question no answer was given, further question was not asked and those many patients recorded in the next format for having none (0) symptoms during the eruption. I $n$ this format, following general informations were included: Date, serial no, name of examiner, age in months, name of child under study, ethnic group, occupation of parents, education of parents, number of siblings and nutrition pattern. The examination procedure and questionnaire was fully explained to the parents of children in their own mother tongue. Linguistic transl ation was carried out and question related to the information to be gathered about systemic manifestations were translated in four primary languages to which population belonged viz. K annada, M arathi, Hindi and English.

\section{Criteria for Selection of Children Population Under Study}

All the children selected were from different socioeconomic groups belonging to different ethnic group and parents speaking different languages, $\mathrm{K}$ annada, $\mathrm{M}$ arathi, Hindi, English. These children werefrom different parts of B el gaum city - N orth west, North east, South west, South east, and attending and procuring facilities extended by Child Development Center at KLES's Hospital and M edical Research Center, Belgaum.

Since, an inherent weakness of questionnaire which after posing question shall prompt an answer, the response could or may have less value than observational study. However, in the present study, children were grouped into group A, group B, group $C$ and group $D$ which belong to less than 12 months, 12 to 18 months, 18 to 24 months and above 24 months respectively.

Answers were prompted in the higher age group $C$ and group $D$ for incisors, canine, molars with present and past memorizing symptoms by the parents. $V$ ariability may be present and value of promptly recorded observation may or may not be lost or to some extent errors would occur due to faulty record by mother. To avoid this, certain information was cross-checked with the information about milestone, provided by Child Development Center.

Data were analyzed by descriptive statistics, i.e. Chi-square analysis.

Chi-square test, $\Sigma(\underline{0-E})^{2},(0$ - observational frequency, $E$ - expected frequency).

\section{RESULTS}

The study had a sample size of 500 children, out of which there were 382 males $(76.4 \%)$ and 118 females. Distribution of children according to ethnicity/religion/community wasHindus: $78.6 \%$, M uslims: $15.2 \%$, Christians: $3.4 \%$, Jains: $2.6 \%$, Sikhs: $0.2 \%$, among the parents of children enrolled into the study, $41.6 \%$ were salaried, $39.2 \%$ were professionals and others amounted to $19.2 \%$.

Table 1 shows the observation that were made regarding clinical manifestations during the eruption of incisors irrespective of whether they were maxillary or mandibular in group A. Out of 98 children who belonged to group A, 12 children did not show any clinical manifestation. A total of 19 children exhibited fever-diarrhea, out of which 17 were males and two were females. The abovementioned clinical manifestations were followed by fever-diarrhea-drooling in 16 children, fever al one in 15 children and diarrhea in 13 children. Six children exhibited fever-drooling and 12 exhibited droolingdiarrhea.

In Table 2, 23, 22 and 20 male children failed to exhibit any clinical manifestation during the eruption of incisors, 
canines and molars respectively. Thirty seven out of 125 male children exhibited clinical manifestation of fever-diarrhea which was a higher figure for the male children as against only 16 females who exhibited the same symptoms. However, among 19 male children in group $B$ for molar eruption, all exhibited symptoms of diarrhea. Parent of one male child in this group reported fever-diarrrhea during canine eruption.
In Table 3, out of 105 children examined, 22, 42 and 48 of male children exhibited symptoms of fever-diarrhea with incisor, canine and molar eruptions respectively.

Table 4 reveal s information given by parents about teething for the group of children above the age of 24 months for incisors (group D), canine and molars. Fever-diarrhea was shown in 17, $8 ; 23,10 ; 16,5$ amongst male and female for the eruption of

Table 1: Distribution of the clinical manifestations in the children for group A (less than 12 months)

\begin{tabular}{|c|c|c|c|c|c|c|c|c|c|}
\hline & & \multicolumn{8}{|c|}{ Clinical manifestation codes } \\
\hline & & 0 & 1 & 2 & 3 & 4 & 5 & 6 & 7 \\
\hline \multirow[t]{2}{*}{ Incisor } & Total no. of males examined & 10 & 4 & 11 & 12 & 17 & 2 & 10 & 11 \\
\hline & Total no. of females examined & 2 & 1 & 2 & 3 & 2 & 4 & 2 & 5 \\
\hline
\end{tabular}

(For codes refer- Annexure I)

Table 2: Distribution of the clinical manifestation in the children for group B (between 12 to 18 months)

\begin{tabular}{|c|c|c|c|c|c|c|c|c|c|}
\hline & & \multicolumn{8}{|c|}{ Clinical manifestation codes } \\
\hline & & 0 & 1 & 2 & 3 & 4 & 5 & 6 & 7 \\
\hline \multirow[t]{2}{*}{ Incisor } & Total no. of males examined & 23 & 4 & 22 & 7 & 37 & 6 & 15 & 11 \\
\hline & Total no. of females examined & 1 & 0 & 7 & 4 & 16 & 3 & 0 & 4 \\
\hline \multirow[t]{2}{*}{ Canine } & Total no. of males examined & 22 & 0 & 0 & 0 & 1 & 0 & 0 & 0 \\
\hline & Total no. of females examined & 0 & 0 & 1 & 0 & 0 & 0 & 0 & 0 \\
\hline \multirow[t]{2}{*}{ Molar } & Total no. of males examined & 20 & 1 & 19 & 9 & 19 & 1 & 1 & 0 \\
\hline & Total no. of females examined & 0 & 0 & 9 & 4 & 2 & 0 & 0 & 0 \\
\hline
\end{tabular}

(For codes refer - Annexure I)

Table 3: Distribution of the clinical manifestation in the children for group C (between 18 to 24 months)

\begin{tabular}{|c|c|c|c|c|c|c|c|c|c|}
\hline & & \multicolumn{8}{|c|}{ Clinical manifestation codes } \\
\hline & & 0 & 1 & 2 & 3 & 4 & 5 & 6 & 7 \\
\hline \multirow[t]{2}{*}{ Incisor } & Total no. of males examined & 12 & 3 & 22 & 9 & 24 & 6 & 12 & 17 \\
\hline & Total no. of females examined & 3 & 0 & 5 & 3 & 7 & 3 & 6 & 4 \\
\hline \multirow[t]{2}{*}{ Canine } & Total no. of males examined & 20 & 0 & 42 & 11 & 19 & 1 & 2 & 1 \\
\hline & Total no. of females examined & 3 & 0 & 9 & 2 & 8 & 1 & 2 & 1 \\
\hline \multirow[t]{2}{*}{ Molar } & Total no. of males examined & 14 & 0 & 48 & 12 & 24 & 1 & 4 & 0 \\
\hline & Total no. of females examined & 3 & 0 & 10 & 2 & 11 & 1 & 2 & 1 \\
\hline
\end{tabular}

(For codes refer- Annexure I)

Table 4: Distribution of the clinical manifestation in the children for group D (above 24 months)

\begin{tabular}{|c|c|c|c|c|c|c|c|c|c|}
\hline & & \multicolumn{8}{|c|}{ Clinical manifestation codes } \\
\hline & & 0 & 1 & 2 & 3 & 4 & 5 & 6 & 7 \\
\hline \multirow[t]{2}{*}{ Incisor } & Total no. of males examined & 17 & 0 & 31 & 6 & 17 & 0 & 0 & 0 \\
\hline & Total no. of females examined & 7 & 0 & 13 & 1 & 8 & 0 & 0 & 0 \\
\hline \multirow[t]{2}{*}{ Canine } & Total no. of males examined & 17 & 1 & 12 & 11 & 23 & 1 & 6 & 4 \\
\hline & Total no. of females examined & 5 & 1 & 5 & 2 & 10 & 1 & 4 & 2 \\
\hline \multirow[t]{2}{*}{ Molar } & Total no. of males examined & 23 & 0 & 25 & 6 & 16 & 0 & 0 & 0 \\
\hline & Total no. of females examined & 9 & 0 & 11 & 2 & 5 & 1 & 0 & 0 \\
\hline
\end{tabular}

(For codes refer- Annexure I) 


\begin{tabular}{|ll} 
& Annexure I \\
\hline Code 1 & Drooling \\
Code 2 & Diarrhea \\
Code 3 & Fever \\
Code 4 & Fever-Diarrhea \\
Code 5 & Fever-Drooling \\
Code 6 & Drooling-Diarrhea \\
Code 7 & Fever-Drooling-Diarrhea \\
\hline
\end{tabular}

incisor, canine and molar as per the information given by the parent. Fever-diarrhea-drooling evaluated zero number of children for the above mentioned clinical manifestation for incisors and molars whereas canine eruption was noted specifically by parents amongst male and female as four and two respectively.

As against group $C$ less number of males exhibited symptoms of fever-diarrhea, i.e. 17, 23 and 16 of male children showed the above mentioned during incisor, canine and molar eruption respectively. This could be associated with increased immunity towards the infection with the advancing age.

\section{DISCUSSION}

A common area of concern among dentist, physician and parent is whether or not teething is responsible for systemic/clinical disturbances. Parents frequently complain while giving medical history of their child that child was well, except during teething. Despite inconsistency professional, health care workers persist teething to explain as the childhood system as well as local oral distress.

It was seen that maximum number of cases infant suffered from one complication at sometime during the eruption period. This finding was in accordance with result of previous studies. ${ }^{7}$ Epidemiological survey is not a mechanistic matter based on knowledge of clinical diagnosis alone. Survey requires relating socioeconomic status to an understanding of society in which they dwell. Data were examined in any relationship between occupation of parents and types of clinical manifestation with different type teeth eruption viz. incisor, canine, molar. This relationship was found to be statistically independent with each other.

Frequency of children having diarrhea among the children of professional group was highest irrespective of incisor, canine and molar. However, independent are the two parameters, diarrhea ranks the highest among all clinical manifestations within any group of occupation of parent.

No statistical evaluation was carried out for parameters included in the format, e.g. ethnic group and siblings. As this parameter should be studied through sociocultural belief of the religion. Further study could be carried out, however, this was not the preview of this study.

Inclusion of sibling information was taken in special structured format only to relate physiological and psychological

need which requires gathering of detailed information about day-to-day life and upbrining of different culture and religion.

The study was limited by population who were sal aried class as the survey was conducted on only 500 children which may not be representative of other population. Further research need for larger population with potentially making their way to take part in such survey during the teeth eruption. M others are usually first to notice a slight deviation from child's normal behaviour or appearance. Important factor of survey was recorded as eruption of each tooth within different group was already in progress. Mother's judgment was accepted as sufficient in determining and providing the information about clinical manifestation. Relationship specifically between education of mother to clinical manifestations with different type of teeth erupting was found to be statistically independent. Our study was in discordance with J aber L, C ohen IJ , M or A (1992) ${ }^{8}$ who established there is no correlation between fever and eruption of teeth, however, as he has mentioned such a common disturbance of low grade fever and diarrhea should be attributed only after ruling out other pathology. The study showed more number of children in group $A$ (less than 12 months) manifested drooling symptoms. As the age advances within group $B$ (between 12 and 18 months), group $C$ (between 18 and 24 months) and group $D$ (above 24 months), clinical manifestation of drooling of saliva was found to be reduced. These manifestation are seen more in group $A$.

Group A (less than 12 months) and group B (between 12 and 18 months), the findings are in accordance with Pertez B enjamin, Ram Diana, Hermida B, Otero M M argrita M aria (2003). ${ }^{5}$ It was observed that more males demonstrated drooling than females.

The results of study showed that $87.78 \%$ (group A); $57.8 \%$ (group B); $57.55 \%$ (group C); $25.7 \%$ (group D) of children with erupting teeth demonstrated general clinical symptoms like drooling, diarrhea, fever. These symptoms could appear al one or in combination with others.

The findings are in accordance with results of study carried out by Carpenter James V (1978). ${ }^{9}$ The presence of feverdiarrhea in this study within group $A$, group $B$, group $C$ and group $D$ showed highest number of children by the manifestation than any other codes eval uated in the study.

Present data demonstrate association between fever-diarrhea observed in all the group consistently when ranked numerically. As the age advances this fever-diarrhea for group $C$ and group $D$ rank second and third. This ranking in group $A$ and group $B$ at its highest position and attributable to lower immunity of infants.

Due to the subjective nature of the information provided by parents, it was difficult to separate the signs and symptoms related to dental eruption from changes of behavior of child based only on parent's views. It is the fact that there was presence of symptoms during eruption of primary teeth focusing on 
objective sign shall overcome possible bias that could be present in our data, which was solely obtained from the parent.

M odern pediatric dentistry drop maternal complaints into teething basket, they must search further causes of fever and diarrhea and must deal with colic, excessive crying, sleep problem and more probable basis (Honig Paul J 1975). ${ }^{10}$

\section{CONCLUSION}

Present data demonstrate association between fever-diarrhea observed in all the group consistently when ranked numerically. As the age advances, this fever-diarrhea for group $C$ and group $D$ rank second and third. This ranking in group $A$ and group $B$ at its highest position is attributable to lower immunity of infants. Further, virology study should be conducted on the subjects to demonstrate any possible occurrence of systemic disturbance.

In conclusion, it is of utmost important that such surveys should be carried out with the help of certified pediatrician. However, in the light of information gathered through parents it is shown that there is definite correl ation between eruption of teeth and clinical/systemic disturbance.

\section{REFERENCES}

1. Shapira Joseph, Ajzman Gisela Berenstein, Engelhard Dan, Cahan Sorel, Kalickman, Barak Vivian. Cytokine level in gingival crevicular fluid of erupting primary teeth correlated with systemic disturbances accompanying teething. Paediatrics Dentistry 2003;25:441-48.

2. Macknin M ichael L, Piedmonte marion, Jacobs J onathan, Skibinski Christine. Symptoms associated with infant teething: A prospective study. J ournal of Paediatrics 2000;105:747-52.

3. Seward MH. Local disturbances attributed to eruption of the human primary dentition: A survey. British Dental Journal 1971;130:72.

4. Seward M H. General disturbances attributed to eruption of the human primary dentition. Journal of Dentistry for Children 1972;39:173-83.

5. Pertez B enjamin, et al. Systemic manifestation during eruption of primary teeth in infants. Journal of Dentistry for Children 2003;170-73.

6. Wake M elissa, Hesketh K ylie, L ucas J ames. Teething and tooth eruption in infants: A cohort study. Journal of Paediatrics 2000;106(6):1374-79.

7. Chakraborty A, Sarkar S, Dutta BB. Localized disturbances associated with primary teeth eruption. J ournal of Indian Society of Pedodontics and Preventive Dentistry 1994;12: 25-28.

8. Jaber $L$, Cohen, M or A. Fever associated with teething. A rch Dis Child 1992;67:233-34.

9. Carpentar James $V$. The relationship between teething and systemic disturbances. J ournal of Dentistry For Children 1978;45:381-84.

10. Honig Paul J. Teething-A re today's paediatricians using yesterday's notation? J ournal of Paediatrics 1975;87:415-17. 